\title{
Activation and Impaired Tumor Necrosis Factor-a Production of Circulating Mucosal-Associated Invariant T Cells in Patients with Trauma
}

\author{
Young-Goun Jo ${ }^{\mathrm{a}}$ Hye-Mi Jin ${ }^{\mathrm{b}}$ Young-Nan Cho ${ }^{\mathrm{b}}$ Jung-Chul Kim ${ }^{\mathrm{a}}$ \\ Seung-Jung Kee ${ }^{c}$ Yong-Wook Park ${ }^{b}$ \\ a Department of Surgery, Chonnam National University Medical School and Hospital, Gwangju, Republic of Korea; \\ ${ }^{b}$ Department of Rheumatology, Chonnam National University Medical School and Hospital, Gwangju, Republic of \\ Korea; ' Department of Laboratory Medicine, Chonnam National University Medical School and Hospital, Gwangju, \\ Republic of Korea
}

\section{Keywords}

Mucosal-associated invariant T cells · Proinflammatory cytokine $\cdot$ Trauma $\cdot$ Tumor necrosis factor-a

\begin{abstract}
Mucosal-associated invariant T (MAIT) cells rapidly produce proinflammatory cytokines in an innate-like manner and play an important role in controlling the host immune response. This study examined the function of MAIT cells in trauma patients. The expression of cytokines in peripheral blood MAIT cells was measured by flow cytometry. MAIT cells in trauma patients displayed impaired tumor necrosis factor (TNF)-a production, together with elevated CD69 expression. The expression of CD69 was negatively correlated with MAIT cell frequency. These patients had higher plasma levels of interleukin (IL)-12 and IL-18. In particular, CD69 expression of MAIT cells was increased by stimulation with IL18 in synergy with other proinflammatory cytokines or plasma of trauma patients. The production of TNF-a by MAIT cells was characterized by an initial burst and rapid decline, in contrast to delayed and sustained production of interferon (IFN)- $\gamma$. Activated MAIT cells showed a functional defect in the production of TNF-a upon restimulation. This study demonstrates that circulating MAIT cells are activated and
\end{abstract}

\begin{tabular}{ll}
\hline KARGER & ( 2019 The Author(s) \\
& Published by S. Karger AG, Basel Oparger \\
E-Mail karger@karger.com & This article is licensed under the Creative Commons Attribution- \\
www.karger.com/jin & NonCommercial-NoDerivatives 4.0 International License (CC BY- \\
NC-ND) (http://www.karger.com/Services/OpenAccessLicense). \\
Usage and distribution for commercial purposes as well as any dis- \\
tribution of modified material requires written permission.
\end{tabular}

functionally impaired in TNF-a production in patients with trauma. The activation and dysfunction of MAIT cells was mediated by proinflammatory cytokines. These findings provide important information underlying the innate immune response of patients with trauma.

(c) 2019 The Author(s)

Published by S. Karger AG, Basel

\section{Introduction}

Trauma represents one of the major causes of death and disability worldwide. According to the Global Burden of Disease and Injury study, 973 million people sustained traumatic injuries and 4.8 million people died from their injuries in 2013 [1]. Severe traumatic injury evokes an acute, non-specific, systemic inflammatory response syndrome (SIRS). It is associated with poor outcome after trauma, paradoxically reducing the body's ability to fight infection [2,3], although the purpose of the inflammatory response is to protect the body against infection. After tissue damage, the injured tissues or activated immune cells release endogenous factors such as damage-associated

Y.-G.J. and H.-M.J. contributed equally to this work.
Dr. Yong-Wook Park or Dr. Seung-Jung Kee

Chonnam National University Medical School and Hospital

42 Jebong-ro, Dong-gu

Gwangju 61469 (Republic of Korea)

E-Mail parkyw@jnu.ac.kr or sjkee@jnu.ac.kr 
molecular patterns (DAMPs) or alarmins $[2,4]$, which are potent activators of innate immune cells (e.g., neutrophils and monocytes) and complement (e.g., C3a and C5a), via cell-surface DAMP receptors [2,5-7]. Activation of inflammatory and complement systems triggers the production of cytokines and chemokines, thereby generating SIRS [8]. The degree of immune system activation is related to the levels of such cytokines, and is associated with mortality, multipleorgan dysfunctionsyndrome(MODS), and sepsis [9]. Therefore, a better understanding of the activation of innate immune response by trauma may lead to novel strategies for the improvement of patient outcome after trauma [2].

Mucosal-associated invariant T (MAIT) cells are innate lymphocytes that express a conserved invariant $\mathrm{T}$ cell receptor (TCR) Va7.2-Ja33 chain paired with a limited set of V $\beta$ chains [10]. MAIT cells are mainly found in the peripheral blood and other tissues like liver, lung, and mucosa [11]. Using distinct pairs of TCR chains, MAIT cells recognize bacteria-derived riboflavin (vitamin $B_{2}$ ) metabolites presented by the MHC class $1 \mathrm{~b}$-like related protein (MR1) $[10,12]$. Upon MR1-dependent recognition of antigens, MAIT cells are activated to rapidly release Th1/Th17 proinflammatory cytokines, including interferon (IFN)- $\gamma$, tumor necrosis factor (TNF)- $\alpha$, and interleukin (IL)-17, and cytotoxic molecules like granzyme and perforin to kill infected host cells [13]. MAIT cells are also activated in an MR1-independent manner, depending on IL-18 expression in synergy with other inflammatory cytokines. Previous reports show that MAIT cells express increased levels of IL-18Ra and IL-12R [14], and are activated by IFN- $\alpha$, IL-15, and IL-12+IL-18 in the absence of exogenous antigens [1517].

Our previous study demonstrated that MAIT cells are deficient in multiple trauma patients and their deficiency is associated with the severity of trauma [18]. MAIT cells play an important role in the innate immune response to traumatic injury. However, little is known about the functional activation of MAIT cells in trauma. Accordingly, the goal of this study was to examine the production capacity of cytokines in peripheral blood MAIT cells of trauma patients.

\section{Patients and Methods}

\section{Patients}

The study cohort was composed of 16 patients with trauma (6 females and 10 males; mean age \pm standard deviation [SD] $61.4 \pm$ 15.2 years) who visited the Chonnam National University Hospi-
Table 1. Clinical and laboratory characteristics of the 16 trauma patients

\begin{tabular}{lc}
\hline Parameters & Findings \\
\hline Sex (male/female) & $10 / 6$ \\
Age, years & $61.4 \pm 15.2$ \\
\hline Clinical variables & \\
APACHE II score & $11.1 \pm 9.9$ \\
SAPS II score & $29.5 \pm 16.4$ \\
ISS score & $18.5 \pm 10.6$ \\
ISS categories, & \\
$\quad$ Mild $(<9)$ & $2(12.5)$ \\
$\quad$ Moderate $(9-15)$ & $4(25)$ \\
$\quad$ Severe $(>15)$ & $10(62.5)$ \\
Mortality & $3(18.75)$
\end{tabular}

\section{Laboratory variables}

Leukocytes, cells/ $\mu \mathrm{L}$

Lymphocytes, cells/ $\mu \mathrm{L}$

$9,019 \pm 2,828$

Neutrophils, cells $/ \mu \mathrm{L}$

Monocytes, cells $/ \mu \mathrm{L}$

$1,127 \pm 474$

Hemoglobin, g/dL

$7,208 \pm 2,635$

$639 \pm 313$

Platelets, $\times 10^{3} / \mu \mathrm{L}$

Bilirubin, $\mathrm{mg} / \mathrm{dL}$

$10.9 \pm 1.7$

$140 \pm 41$

$0.9 \pm 0.4$

BUN, mg/dL

Creatinine, $\mathrm{mg} / \mathrm{dL}$

$18.8 \pm 15.9$

$1.4 \pm 1.9$

$4.8 \pm 5.5$

CRP, mg/dL

$\mathrm{PaO}_{2}, \mathrm{~mm} \mathrm{Hg}$

$100.8 \pm 38.4$

Lactate, $\mathrm{mmol} / \mathrm{L}$

$2.9 \pm 2.0$

Bicarbonate, $\mathrm{mmol} / \mathrm{L}$

Prothrombin time (INR)

MAP, $\mathrm{mm} \mathrm{Hg}$

$23.0 \pm 5.1$

$1.30 \pm 0.32$

$78 \pm 22$

Heart rate, beat/min

Body temperature, ${ }^{\circ} \mathrm{C}$

$102 \pm 25$

$37.1 \pm 0.5$

Data are presented as $n(\%)$ or the mean \pm SD. APACHE, Acute Physiology and Chronic Health Evalution; SAPS, Simplified Acute Physiology Score; ISS, Injury Severity Score; BUN, blood urea nitrogen; $\mathrm{CRP}, \mathrm{C}$-reactive protein; $\mathrm{PaO}_{2}$, partial pressure of oxygen in arterial blood; INR, international normalized ratio; MAP, mean arterial pressure.

tal Regional Trauma Center after the trauma and 16 non-injured healthy controls (HCs; 7 females and 9 males; mean age \pm SD $52.4 \pm 5.5$ years). All blood samples were usually obtained from the patients within $12-36 \mathrm{~h}$ after the traumatic injury. The clinical and laboratory characteristics of the patients are summarized in Table 1.

Monoclonal Antibodies and Flow Cytometry

The following monoclonal antibodies (mAbs) and reagents were used in this study: allophycocyanin (APC)-Cy7-conjugated anti-CD3 (SK7), phycoerythrin (PE)-Cy5-conjugated anti-CD161 (DX12) and fluorescein isothiocyanate (FITC)-conjugated antiTCR $\gamma \delta(11 F 2)$, FITC-conjugated anti-CD3 (HIT3a), FITC-conjugated anti-IFN- $\gamma$ (B27), FITC-conjugated annexin V, PE-conju- 
gated anti-CD3(HIT3a), PE-conjugated anti-IL-17 (SCPL1362), PE-Cy7-conjugated anti-TNF- $\alpha$ (MAb11), PE-conjugated antiCD69 (FN50), FITC-conjugated mouse IgG isotype (X40), PEconjugated mouse IgG isotype (X40) and PE-Cy7-conjugated mouse IgG isotype (MOPC-21) control (all obtained from Becton Dickinson, San Diego, CA, USA), PE-conjugated anti-programmed death-1 (anti-PD-1; MIH4; eBioscience, San Diego, CA, USA) and APC-conjugated anti-TCR Va7.2 (3C10; BioLegend, San Diego, CA, USA). Cells were stained with combinations of appropriate $\mathrm{mAb}$ for $20 \mathrm{~min}$ at $4{ }^{\circ} \mathrm{C}$. The stained cells were analyzed on a Navios flow cytometer using Kaluza software (version 1.5a; Beckman Coulter, Brea, CA, USA). MAIT cells were identified phenotypically as $\mathrm{CD} 3+\mathrm{TCR} \gamma \delta-\mathrm{V} \alpha 7.2+\mathrm{CD} 161^{\text {high }}$ cells using flow cytometry as previously described $[19,20]$.

\section{Functional MAIT Cell Assay}

The expression of IFN- $\gamma$, IL-17, and TNF- $\alpha$ in MAIT cells was detected by intracellular cytokine flow cytometry as previously described [20]. To determine the CD69 expression in MAIT cells after stimulation with cytokine cocktail or plasma from trauma patients, freshly isolated PBMCs $\left(1 \times 10^{6} /\right.$ well $)$ were stimulated with a proinflammatory cytokine cocktail consisting of IL-6 (50 ng/mL; PeproTech), IL-8 (10 ng/mL; PeproTech), IL-12 (50 ng/ mL; Miltenyi Biotec, Bergisch Gladbach, Germany), IL-18 (50 ng/ $\mathrm{mL}$; Medical and Biological Laboratories, Woburn, MA, USA), and TNF- $\alpha$ ( $5 \mathrm{ng} / \mathrm{mL}$; PeproTech) for $24 \mathrm{~h}$, or stimulated with 300 $\mu \mathrm{L}$ of trauma patient plasma for 3 days. Cells were stained with FITC-conjugated anti-CD3, APC-conjugated anti-TCR Va7.2, PE-conjugated anti-CD69, and PE-Cy5-conjugated anti CD161 $\mathrm{mAbs}$ for $20 \mathrm{~min}$ at $4{ }^{\circ} \mathrm{C}$. CD69+ MAIT cells were determined by flow cytometry. Blocking antibodies for cytokines included antiIL-18 (5 $\mu \mathrm{g} / \mathrm{mL}$; R\&D Systems) and anti-IL-6 (5 $\mu \mathrm{g} / \mathrm{mL})$, anti-IL-8 $(5 \mu \mathrm{g} / \mathrm{mL})$, anti-IL-12 $(5 \mu \mathrm{g} / \mathrm{mL})$, and anti-TNF- $\alpha(5 \mu \mathrm{g} / \mathrm{mL}$; all from BD Biosciences).

To determine the production of IFN- $\gamma$ and TNF- $\alpha$ by MAIT cells after restimulation, freshly isolated PBMCs were stimulated with Dynabeads Human T-Activator CD3/CD28 (Life Technologies) and cytokine cocktail consisting of IL-6 (50 ng/mL), IL-8 (10 $\mathrm{ng} / \mathrm{mL}), \mathrm{IL}-12$ (50 ng/mL), IL-18 (50 ng/mL), and TNF- $\alpha$ (5 ng/ $\mathrm{mL}$ ) for $16 \mathrm{~h}$. The cells were washed to remove the activating factors and cultured with IL-2 (100 U/mL; BD Pharmingen) to support cell survival for 1 day. Later, cells were restimulated for $16 \mathrm{~h}$ with the same stimulators. The production of IFN- $\gamma$ and TNF- $\alpha$ by MAIT cells was determined by intracellular flow cytometry as described above.

\section{Statistical Analysis}

The expression levels of IFN- $\gamma$, IL-17, TNF- $\alpha$, CD69, annexin $\mathrm{V}$, and PD-1 in MAIT cells between HCs and patients were compared by analysis of covariance after adjusting for age and sex using Bonferroni correction for multiple comparisons. The expression of IFN- $\gamma$, TNF- $\alpha$, and CD69 between unstimulated and stimulated or between stimulated and restimulated MAIT cells was compared using a paired $t$ test. The Mann-Whiney $\mathrm{U}$ test was used to compare plasma levels of cytokines in trauma patients versus age- and sex-matched HCs. Spearman's correlation analysis was used to examine the relationships between MAIT cell percentages and CD69+ MAIT cells, annexin V+ MAIT cells, or PD-1+ MAIT cells. $p$ values $<0.05$ were considered statistically significant. Statistical analysis and graphic works were performed using SPSS version
18.0 software (SPSS, Chicago, IL, USA) and GraphPad Prism version 5.03 software (GraphPad Software, San Diego, CA, USA), respectively.

\section{Results}

\section{Impaired TNF- $\alpha$ Production of Circulating MAIT}

\section{Cells in Trauma Patients}

To examine the expression of inflammatory cytokines in MAIT cells, we incubated PBMCs derived from 16 trauma patients and $16 \mathrm{HCs}$ for $4 \mathrm{~h}$ in the presence of phorbol myristate acetate (PMA) and ionomycin (IM). The expression of IFN- $\gamma$, IL-17A, and TNF- $\alpha$ in the MAIT cell populations was determined at the single-cell level by intracellular flow cytometry (Fig. 1a). Percentages of TNF-a-expressing MAIT cells were found to be significantly lower in trauma patients as compared with HCs (median 38.0 vs. $56.2 \%, p<0.01$ ). However, IFN- $\gamma+$ and IL-17A+ MAIT cell levels were comparable between the patients and HCs (Fig. 1b).

\section{Activation of MAIT Cells in Trauma Patients}

Our previous study reported deficiencies of MAIT cell numbers in patients with trauma [18]. To determine whether circulating MAIT cell deficiency is associated with activation-induced cell death, we investigated the activation and apoptosis, indicated by CD69 upregulation and annexin $\mathrm{V}$ staining, respectively, in circulating MAIT cells. CD69+ and annexin V+ MAIT cells were examined by flow cytometry. Percentages of CD69+ MAIT cells were found to be significantly higher in trauma patients than in HCs (median 25.5 vs. 6.1\%; $p<0.0001$, Fig. 2a, b). In particular, the CD69 expression of MAIT cells was inversely correlated with the frequency of MAIT cells in trauma patients $(\gamma=-0.562, p<0.05$; Fig. 2c). However, no significant difference was observed between the annexin $\mathrm{V}+$ MAIT cell levels in patients and HCs $(p=$ 0.25; Fig. 2d, e). Furthermore, no significant correlation was observed between MAIT cell percentages and annexin V+ MAIT cells (Fig. 2f).

To determine whether impaired TNF-a production of MAIT cells was related to PD-1, we evaluated the expression of PD-1 in MAIT cells from 16 patients and $16 \mathrm{HCs}$. The expression of PD-1 in the MAIT cell populations was examined at the single-cell level by flow cytometry (Fig. $2 \mathrm{~g}$ ). Expression levels of PD-1 in MAIT cells were comparable between patients and HCs ( $p=0.64$; Fig. $2 \mathrm{~h})$. No significant correlation was observed between MAIT cell percentages and PD-1+ MAIT cells (Fig. 2i). 
Fig. 1. Decreased expression of TNF- $\alpha$ in MAIT cells of trauma patients. Freshly isolated PBMCs $\left(1 \times 10^{6} /\right.$ well $)$ were incubated for $4 \mathrm{~h}$ in the presence of PMA $(100 \mathrm{ng} / \mathrm{mL})$ and IM $(1 \mu \mathrm{M})$. a Representative IFN- $\gamma$, IL17 , and TNF- $\alpha$ expressions in the MAIT cell population were determined by intracellular flow cytometry after stimulation with PMA and IM. b Data related to IFN- $\gamma+$, IL-17+, and TNF- $\alpha+$ MAIT cells were obtained from $16 \mathrm{HCs}$ and 16 trauma patients. Symbols represent individual subjects and horizontal lines are median values. ${ }^{*} p<0.01$ by the ANCOVA test.
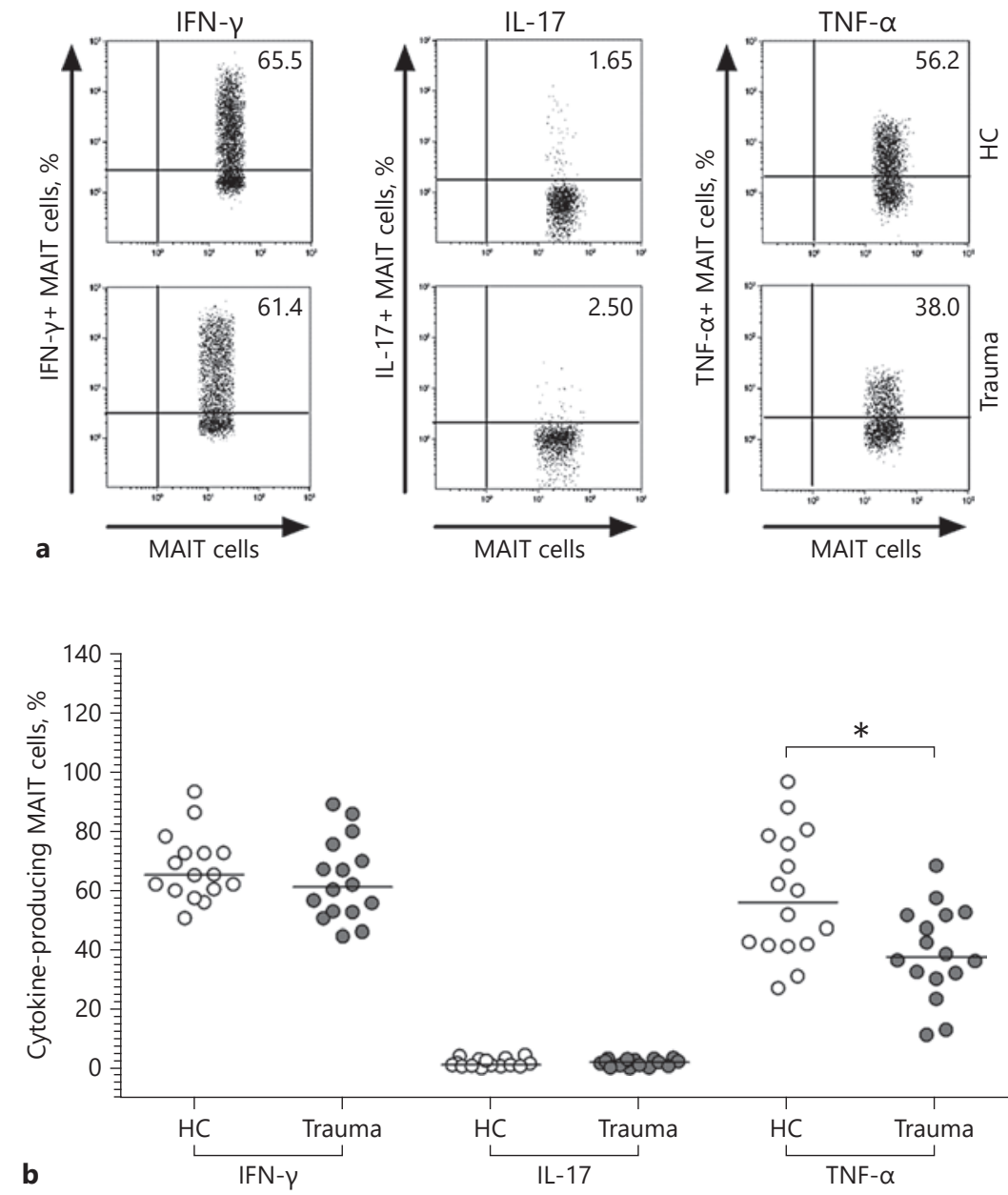

Increased Plasma Levels of IL-12 and IL-18 in Trauma Patients

We measured plasma levels of IL-12 and IL-18, which are known as MAIT cell-activating cytokines [16], using ELISA in 14 trauma patients and 12 HCs. Patients with trauma showed significantly higher plasma levels of IL-12 and IL-18 as compared with HCs (median 27.2 vs. 15.1 $\mathrm{pg} / \mathrm{mL}, p<0.05$; median 196.3 vs. $115.7 \mathrm{pg} / \mathrm{mL}, p<0.0005$; Fig. 3).

\section{Activation of MAIT Cells after Stimulation with \\ Proinflammatory Cytokines or Plasma from Trauma \\ Patients}

To determine whether MAIT cells can be activated by proinflammatory cytokines, including IL-6, IL-8, IL-12, IL-18, and TNF- $\alpha$, which are elevated in the plasma of patients with trauma [21], PBMCs from trauma patients and HCs were cultured with these recombinant cytokines consisting of IL-6, IL-8, IL-12, IL-18, and TNF- $\alpha$ for $24 \mathrm{~h}$ in the presence or absence of cytokine inhibitors (i.e., blocking antibodies against a cocktail of IL-6, IL-8, IL-12, IL-18, and TNF- $\alpha$ and the levels of CD69+ MAIT cells were determined by flow cytometry (Fig. 4a). Percentages of CD69+ MAIT cells were found to be significantly higher in cytokine-treated cultures than in untreated cultures (mean \pm SEM $47.4 \pm 2.27$ vs. $1.2 \pm 0.09 \%, p<0.0005$, for HCs; $82.3 \pm 5.88$ vs. $15.2 \pm 2.49 \%, p<0.001$, for trauma patients, respectively) and then decreased to untreated levels after treatment with blocking antibodies (mean \pm SEM $47.4 \pm 2.27$ vs. $1.7 \pm 0.23 \%, p<0.0005$, for HCs; $82.3 \pm 5.88$ vs. $30.4 \pm 5.15 \%, p<0.005$ for trauma patients, respectively; Fig. 4b).

To examine whether plasma samples obtained from trauma patients affect the activation of MAIT cells, 

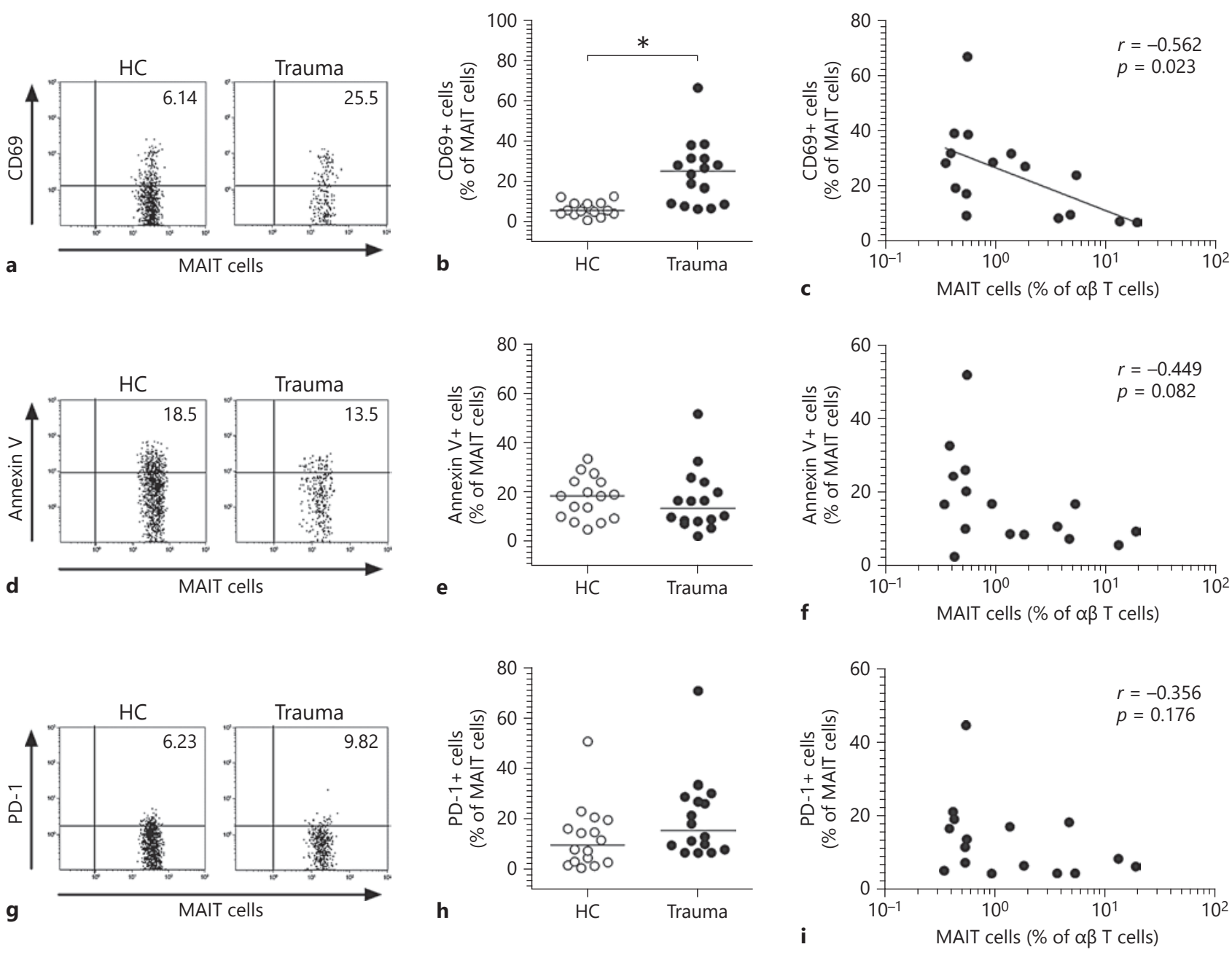

Fig. 2. Expression of CD69 and PD-1 and apoptosis in MAIT cells of trauma patients. Freshly isolated PBMCs were stained with FITC-conjugated anti-CD3, FITC-conjugated annexin V, APCconjugated anti-TCR Va7.2, PE-conjugated anti-CD3, PE-conjugated anti-CD69, PE-conjugated anti-PD-1, and PE-Cy5-conjugated anti-CD161 monoclonal antibodies, and analyzed by flow cytometry. Representative percentages of CD69-expressing cells (a), annexin V-expressing cells (d), and PD-1-expressing cells (g)

PBMCs from HCs were cultured with plasma derived from the patients for 3 days in the presence or absence of the cytokine inhibitors and then CD69+ MAIT cell levels were determined by flow cytometry (Fig. 4c). Percentages of CD69+ MAIT cells were higher in the presence than in the absence of plasma (mean \pm SEM $5.5 \pm 0.90$ vs. $2.8 \pm$ $0.66 \%, p<0.001)$ and were normalized to untreated levels after treatment with blocking antibodies (mean \pm SEM $5.5 \pm 0.90$ vs. $3.6 \pm 0.58 \%, p<0.005$; Fig. 4 d). among the MAIT cell population. Data in $\mathbf{b}$, e, and $\mathbf{h}$ were obtained from $16 \mathrm{HCs}$ and 16 trauma patients. Symbols represent individual subjects and horizontal lines are median values. ${ }^{*} p<$ 0.0001 by the ANCOVA test. Relationships between MAIT cell percentages among the $\alpha \beta$ T cell population and CD69+ MAIT cells (c), annexin V+ MAIT cells (f), or PD-1+ MAIT cells (i) in trauma patients were determined using Spearman's correlation analysis.

\section{Impaired TNF- $\alpha$ Production of MAIT Cells by Restimulation}

Population dynamics of invariant natural killer $\mathrm{T}$ (iNKT) cells in response to a-galactosylceramide ( $\alpha$-GalCer) is characterized by prompt activation and rapid cytokine production with an initial burst of IL-4 (peaks at $2 \mathrm{~h}$ after stimulation) followed by IFN- $\gamma$ (peaks at $24 \mathrm{~h}$ after stimulation) [22]. However, the production of these cytokines gradually diminished to very low levels 


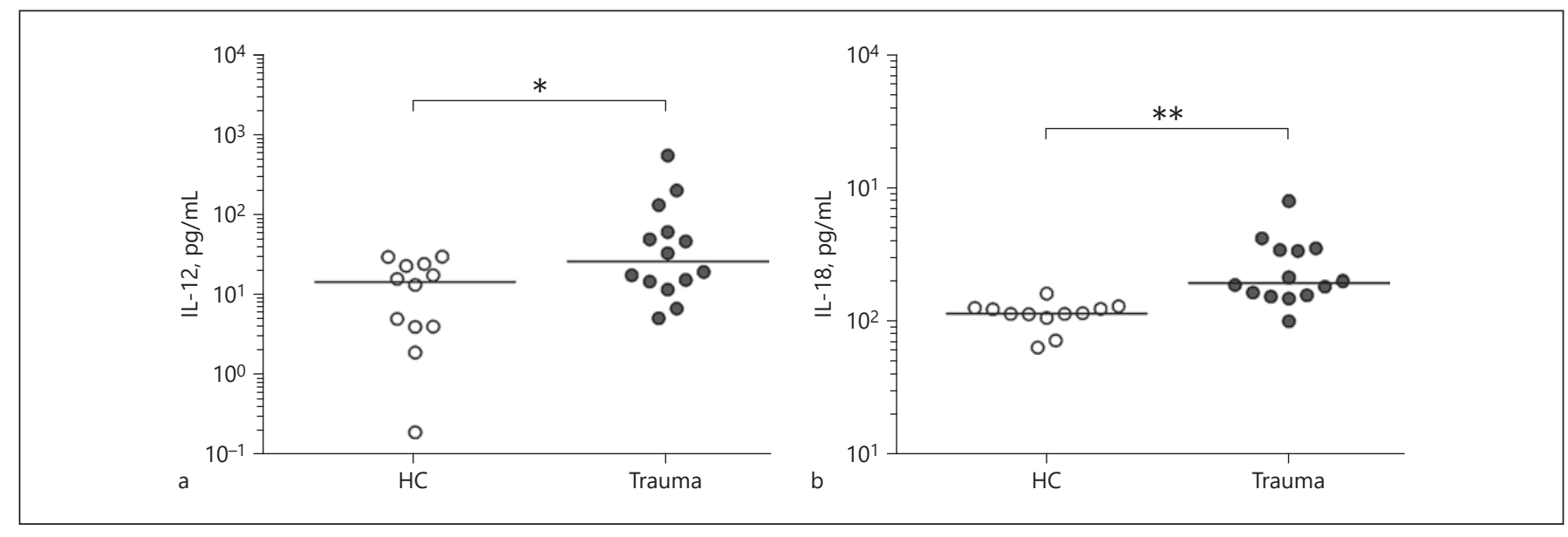

Fig. 3. Plasma levels of IL-12 and IL-18 in trauma patients. Plasma samples of patients were collected before specific treatment on admission. Plasma levels of IL-12 (a) and IL-18 (b) were determined by ELISA. Data were obtained from $12 \mathrm{HCs}$ and 14 trauma pa-

at $72 \mathrm{~h}$ after stimulation. These $\alpha$-GalCer-experienced iNKT cells exhibit functional defects upon $\alpha$-GalCer restimulation [23]. We speculated that the population dynamics of MAIT cells simulated iNKT cell behavior.

To determine the kinetics of cytokine production in MAIT cells after stimulation, PBMCs from HCs were cultured with PMA and IM and the expression of IFN- $\gamma$ and TNF- $\alpha$ in the MAIT cell populations was examined at the single-cell level by intracellular flow cytometry (Fig. 5a). Production of TNF- $\alpha$ by MAIT cells in response to PMA and IM was found to peak at $0.5 \mathrm{~h}$ up to $1 \mathrm{~h}$ after stimulation and rapidly diminish to very low level at $4 \mathrm{~h}$ after stimulation. On the other hand, the percentages of IFN $-\gamma+$ MAIT cells in response to PMA and IM were found to peak at $0.5 \mathrm{~h}$ up to $4 \mathrm{~h}$ after stimulation and gradually diminish to a low level at $36 \mathrm{~h}$.

To investigate whether stimulated MAIT cells exhibited functional defects upon restimulation, PBMCs from HCs were cultured with CD3/CD28 beads and a cytokine cocktail for $16 \mathrm{~h}$ and washed, and then rested for 1 day. After resting, the cells were restimulated with $\mathrm{CD} 3$ / CD28 beads and a cytokine cocktail, including IL-6, IL-8, IL-12, IL-18, and TNF- $\alpha$, for $16 \mathrm{~h}$, and the levels of IFN- $\gamma+$ and TNF- $\alpha+$ MAIT cells were determined by intracellular flow cytometry (Fig. 5b). Upon restimulation, the production of TNF- $\alpha$ by MAIT cells was found to significantly diminish, whereas IFN- $\gamma$ synthesis remained unchanged (stimulation versus restimulation for TNF- $\alpha$ : mean \pm SEM $24.5 \pm 3.64$ vs. $7.2 \pm 0.55 \%, p<0.05$; Fig. 5c, d).

MAIT Cells in Patients with Trauma tients. Symbols represent individual subjects and horizontal lines indicate median values. ${ }^{*} p<0.05,{ }^{* *} p<0.0005$ by the MannWhitney U test.

\section{Discussion}

To the best of our knowledge, this is the first study to assess the function of MAIT cells in trauma patients. The present study showed that the production of TNF- $\alpha$ by MAIT cells was decreased in trauma patients, together with the elevated expression of CD69. In addition, the expression of CD69 was negatively correlated with MAIT cell frequency. These patients had higher plasma levels of IL-12 and IL-18. In particular, the CD69 expression of MAIT cells was increased by stimulation with IL-18 in synergy with other proinflammatory cytokines or plasma of trauma patients and then normalized after treatment with blocking antibodies, suggesting that these cytokines may contribute to MAIT cell activation. Interestingly, the kinetics of cytokine production in MAIT cells varied between IFN- $\gamma$ and TNF- $\alpha$. The production of TNF- $\alpha$ by MAIT cells was characterized by an initial burst and rapid decline, in contrast to the delayed and sustained production of IFN- $\gamma$. Furthermore, activated MAIT cells resulted in a decline in the production of TNF- $\alpha$ upon restimulation. Overall, these findings suggest that an impaired TNF- $a$ production of MAIT cells may be related to innate immune response of patients with trauma.

The present study showed that TNF- $\alpha$ production by MAIT cells was diminished in trauma patients, but their capacity for IFN- $\gamma$ production was preserved, which is consistent with the previous data involving scrub typhus, another acute infectious disease [24]. Conversely, MAIT cells in patients with chronic HIV-1 infection and 


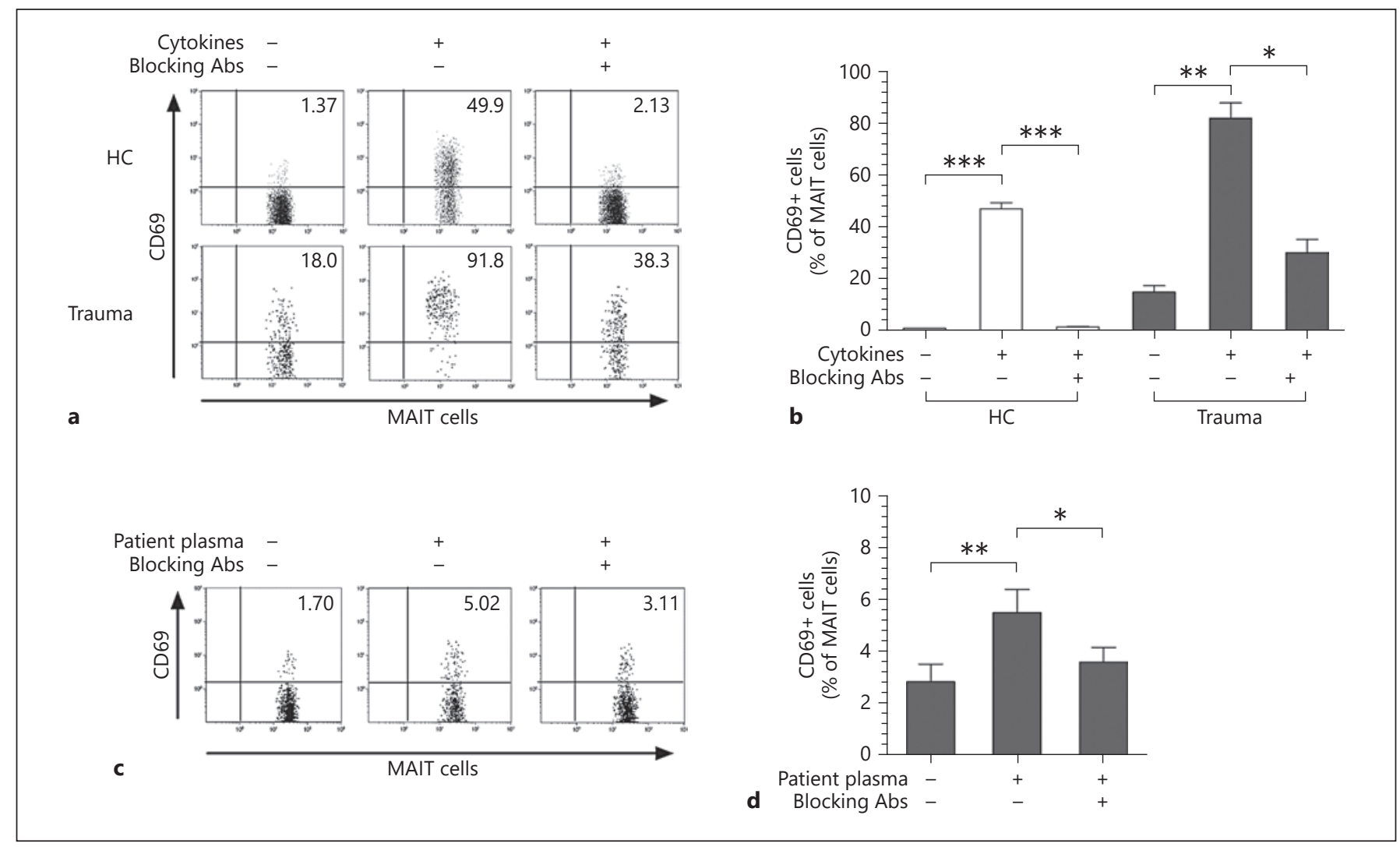

Fig. 4. Effect of stimulation with a proinflammatory cytokine cocktail or patient plasma on the CD69 expression of MAIT cells. a PBMCs $\left(1 \times 10^{6} /\right.$ well $)$ from HCs and trauma patients were incubated for $16 \mathrm{~h}$ in the presence or absence of cytokine inhibitors (i.e., blocking antibodies against a cocktail of IL-6, IL-8, IL-12, IL-18, and TNF- $\alpha$ ) and then stimulated with the cytokine cocktail for 24 h. Data in b were obtained from 4 HCs and 4 trauma patients. c PBMCs $\left(1 \times 10^{6} /\right.$ well $)$ from HCs were incubated for $16 \mathrm{~h}$ in the presence or absence of the cytokine inhibitors and then stimulated

Sjögren's syndrome displayed an additional defect in IFN $-\gamma$ production, together with the impaired TNF- $\alpha$ production $[25,26]$. Furthermore, a defective IFN- $\gamma$ production by MAIT cells has also been observed in other chronic inflammatory or infectious diseases, such as systemic lupus erythematosus (SLE) and tuberculosis [20, 27]. These findings indicate that the differences in MAIT cell dysfunction may be linked to chronic disease, which is possibly explained by the sequential increase in multifunctional defects involving cytokine production by MAIT cells with progressive disease. Under persistent stimulation, MAIT cells may go through a sequential process of dysfunction in cytokine production (i.e., loss of TNF- $\alpha$ synthesis followed by IFN- $\gamma$ loss), similar to T cell exhaustion [28]. Interestingly, recent studies have indi- for 3 days in the presence of plasma from trauma patients. Stimulated cells were stained with FITC-conjugated anti-CD3, APCconjugated anti-TCR Va7.2, PE-conjugated anti-CD69, and PECy5-conjugated anti-CD161 monoclonal antibodies. Representative percentages of CD69-expressing cells among the MAIT cell population. Data in $\mathbf{d}$ were obtained from plasma of 6 trauma patients. Values are expressed as the mean \pm SEM. ${ }^{*} p<0.005,{ }^{* *} p<$ $0.001,{ }^{* * *} p<0.0005$ by the paired $t$ test.

cated a critical role of plasma proinflammatory cytokines, such as TNF- $\alpha$, IL-1, and IFN- $\gamma$ in the induction of posttraumatic apoptosis, resulting in post-traumatic cardiac dysfunction and even MODS [29-31]. Taken together, these findings suggest that defective synthesis of TNF- $\alpha$ by MAIT cells in trauma patients may represent a physiological negative-feedback mechanism, resulting in protection against excessive inflammation.

Based on the duration and extent of activation, effector cells go through immune activation as follows: (i) early activation (e.g., CD69), (ii) chronic activation (e.g., CD38 and HLA-DR), (iii) exhaustion (e.g., PD-1, TIM-3, LAG-3, and CTLA-4), and (iv) senescence (i.e., CD57) [28, 32-36]. In the present study, MAIT cells in trauma patients exhibited a higher frequency of CD69 expression without up- 


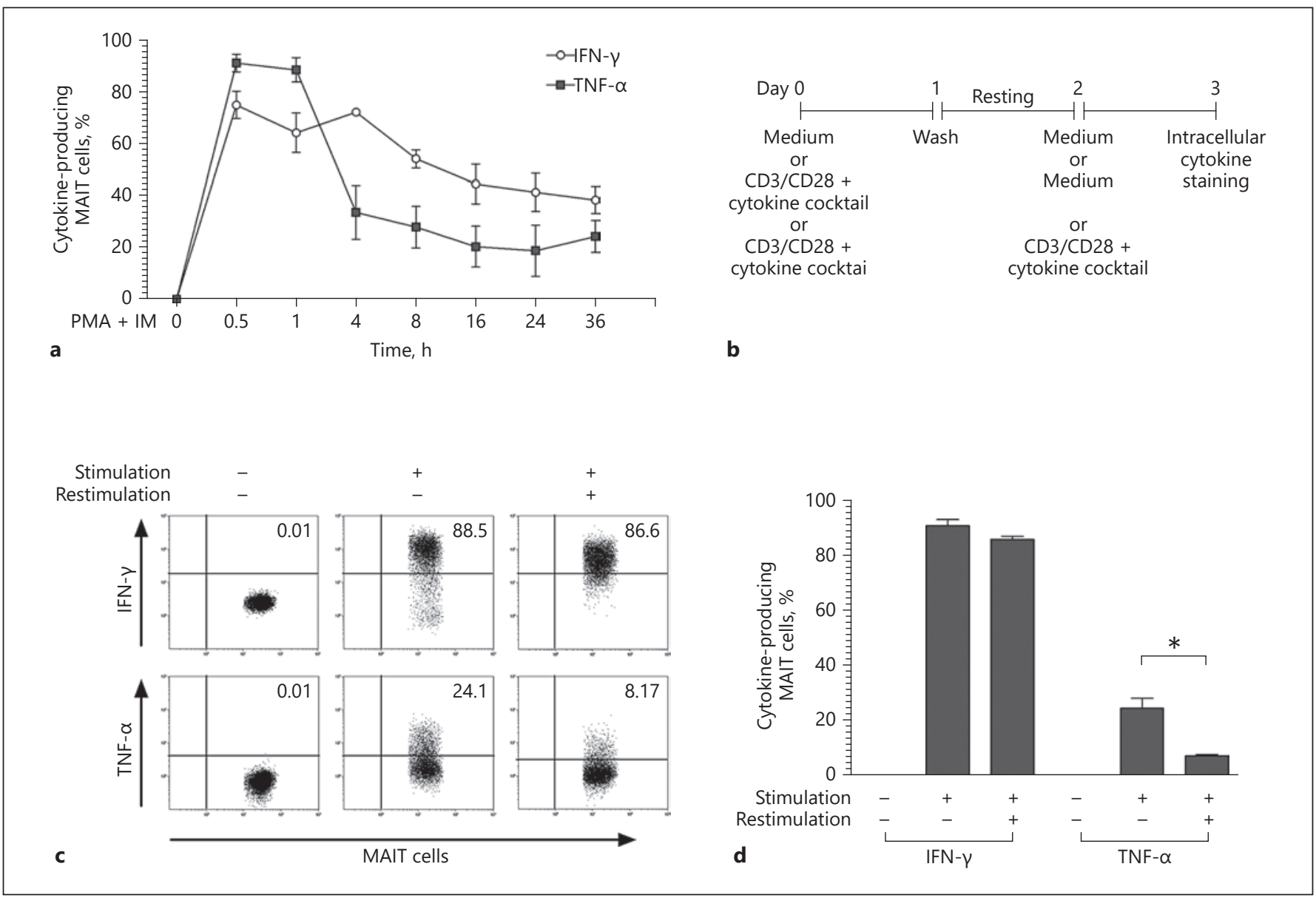

Fig. 5. Reduced TNF- $\alpha$ production of MAIT cells by restimulation. a Time course of IFN- $\gamma$ and TNF- $\alpha$ production during MAIT cell stimulation with PMA $(100 \mathrm{ng} / \mathrm{mL})$ and IM $(1 \mu \mathrm{M})$. b-d PBMCs $\left(1 \times 10^{6} /\right.$ well) from 3 HCs were stimulated with CD3/CD28 beads and a cytokine cocktail for $16 \mathrm{~h}$, washed to remove activating factors, and cultured with IL-2 $(100 \mathrm{U} / \mathrm{mL})$ to support cell survival for
1 day. Subsequently, cells were restimulated for $16 \mathrm{~h}$ with CD3/ CD28 beads and a cytokine cocktail. Percentages of IFN- $\gamma$ and TNF- $\alpha$ in MAIT cells were determined by intracellular flow cytometry. Values are expressed as the mean \pm SEM. ${ }^{*} p<0.05$ by the paired $t$ test. regulation of $\mathrm{PD}-1$, in line with our previous study involving scrub typhus [24]. In contrast, CD69 and PD-1 expression of MAIT cells were upregulated in patients with chronic infectious or inflammatory diseases, such as tuberculosis, chronic HCV infection, and SLE [17, 20, 37, 38]. Furthermore, CD69 expression in MAIT cells was correlated with the ankylosing spondylitis disease activity score and SLE disease activity index in patients with ankylosing spondylitis and SLE, respectively [17, 39]. Collectively, these findings suggest that distinct profiles of activation and exhaustion markers may reflect disease activity and the degree of activation of MAIT cells in specific diseases.

Our data revealed that the plasma levels of IL-12 and IL-18 were elevated in trauma patients, which is consistent with other studies reporting that plasma levels of proinflammatory cytokines, such as IL-1 $\beta$, IL-2, IL-6, IL8 , IL-12, IL-18, TNF- $\alpha$, and IFN- $\gamma$, were significantly increased in trauma patients with seldom detectable levels of IL-2 and IFN- $\gamma[21,40]$. Furthermore, our study demonstrated that unstimulated MAIT cells in healthy individuals were activated in response to stimulation with plasma from trauma patients or exogenous proinflammatory cytokines, including IL-6, IL-8, IL-12, IL-18, and TNF- $\alpha$. The MAIT cell activation was normalized after treatment with blocking antibodies against the cytokines. However, it remains unclear which cytokines drive the CD69 upregulation. The CD69 upregulation by MAIT cells in response to cytokines was significantly blocked by each of anti-IL-12, anti-IL-18, and anti-TNF- $\alpha$ antibodies, and not by anti-IL- 6 and anti-IL- 8 antibodies, indi- 
cating that IL-12, IL-18, and TNF- $\alpha$ are responsible for the CD69 upregulation (see online suppl. Fig. 1; for all online suppl. material, see www.karger.com/ doi/10.1159/000499343). Additional analysis including trauma patients showed that the activation behavior of patient-derived MAIT cells was similar to that of healthy individuals. The only difference is that the baseline activation level is higher in the patients than in healthy individuals. Recent reports show that MAIT cells, which are known to highly express IL-18Ra and IL-12R, can be activated by IFN- $\alpha$, IL-15, and IL-12+IL-18 in the absence of exogenous antigens, the concentrations of which are positively correlated with the expression of CD69 on MAIT cells [15-17]. In our study, the CD69 upregulation by patient plasma was not completely blocked by anticytokine antibodies against IL-6, IL-8, IL-12, IL-18, and TNF- $\alpha$, suggesting that other plasma cytokines or factors besides those five cytokines may drive the response. Collectively, these findings indicate that the activation of MAIT cells in trauma is mediated via increased expression of plasma proinflammatory cytokines, such as IL-12, IL-18, and TNF- $\alpha$, in an MR1-independent manner.

The mechanism of defective TNF- $\alpha$ production in circulating MAIT cells of patients with trauma remains to be elucidated. A possible explanation is that this dysfunction may be due to the different kinetics of release of each cytokine from the MAIT cells, which is supported by our in vitro study showing differential secretion of IFN- $\gamma$ and TNF- $\alpha$ from MAIT cells. The different kinetics of IFN- $\gamma$ and TNF- $\alpha$ secretions was also observed in a traumatized rat model [31]. Furthermore, MAIT cells exposed to a traumatic environment may rapidly lose the ability to produce TNF- $\alpha$. This hypothesis is corroborated by our data showing that stimulated MAIT cells exhibit a functional defect in the production of TNF- $\alpha$ upon restimulation. Further studies are needed to investigate the molecular and signaling pathways directly mediating the impaired TNF-a production in MAIT cells of trauma patients.

\section{Conclusions}

The present study demonstrates that circulating MAIT cells are activated and functionally impaired in TNF- $\alpha$ production of patients with trauma. In addition, the activation and dysfunction of MAIT cells were mediated via proinflammatory cytokines. These findings provide important insight into the innate immune response of patients sustaining trauma.

\section{Acknowledgments}

This study was supported by the National Research Foundation of Korea funded by the Korean Government (grants 2015R1D1A4A01019017, 2015R1D1A1A01059762, 2016R1A6A3 A11930514, and 2017R1D1A1B03029239), and the Chonnam National University Hospital Biomedical Research Institute (grant CRI17028-1 and CRI18092-1).

\section{Statement of Ethics}

The study protocol was approved by the Institutional Review Board of Chonnam National University Hospital, and written informed consent was obtained from all participants in accordance with the Declaration of Helsinki.

\section{Disclosure Statement}

The authors declare that they have no competing interests.

\section{Author Contributions}

Y.-G.J., H.-M.J., Y.-N.C., J.-C.K., S.-J.K., and Y.-W.P. designed the study, collected clinical information, analyzed the raw data, performed the statistical analysis, and contributed to writing the paper. Y.-G.J., H.-M.J., and Y.-N.C. performed the experiments. All the authors read and approved the final version of the manuscript.

\section{References}

1 Haagsma JA, Graetz N, Bolliger I, Naghavi M, Higashi $H$, Mullany EC, et al. The global burden of injury: incidence, mortality, disability-adjusted life years and time trends from the Global Burden of Disease study 2013. Inj Prev. 2016 Feb;22(1): 3-18.

2 Manson J, Thiemermann C, Brohi K. Trauma alarmins as activators of damage-induced inflammation. Br J Surg. 2012 Jan;99(S1 Suppl 1):12-20.
3 Lord JM, Midwinter MJ, Chen YF, Belli A, Brohi K, Kovacs EJ, et al. The systemic immune response to trauma: an overview of pathophysiology and treatment. Lancet. 2014 Oct;384(9952):1455-65.

4 Zhang Q, Raoof M, Chen Y, Sumi Y, Sursal T, Junger $\mathrm{W}$, et al. Circulating mitochondrial DAMPs cause inflammatory responses to injury. Nature. 2010 Mar;464(7285):104-7.

5 Burk AM, Martin M, Flierl MA, Rittirsch D, Helm M, Lampl L, et al. Early complemen- topathy after multiple injuries in humans. Shock. 2012 Apr;37(4):348-54.

6 Neher MD, Weckbach S, Flierl MA, HuberLang MS, Stahel PF. Molecular mechanisms of inflammation and tissue injury after major trauma-is complement the "bad guy"? J Biomed Sci. 2011 Nov; 18(1):90.

7 Huber-Lang M, Kovtun A, Ignatius A. The role of complement in trauma and fracture healing. Semin Immunol. 2013 Feb;25(1): 73-8. 
8 Ward PA. The dark side of C5a in sepsis. Nat Rev Immunol. 2004 Feb;4(2):133-42.

9 Medzhitov R. Origin and physiological roles of inflammation. Nature. 2008 Jul;454(7203): 428-35.

10 Treiner E, Duban L, Bahram S, Radosavljevic M, Wanner V, Tilloy F, et al. Selection of evolutionarily conserved mucosal-associated invariant T cells by MR1. Nature. 2003 Mar; 422(6928):164-9.

11 Le Bourhis L, Guerri L, Dusseaux M, Martin E, Soudais C, Lantz O. Mucosal-associated invariant $\mathrm{T}$ cells: unconventional development and function. Trends Immunol. 2011 May; 32(5):212-8.

12 Kjer-Nielsen L, Patel O, Corbett AJ, Le Nours J, Meehan B, Liu L, et al. MR1 presents microbial vitamin B metabolites to MAIT cells. Nature. 2012 Nov;491(7426):717-23.

13 Napier RJ, Adams EJ, Gold MC, Lewinsohn DM. The role of mucosal associated invariant $\mathrm{T}$ cells in antimicrobial immunity. Front Immunol. 2015 Jul;6:344.

14 Shaler CR, Choi J, Rudak PT, Memarnejadian A, Szabo PA, Tun-Abraham ME, et al. MAIT cells launch a rapid, robust and distinct hyperinflammatory response to bacterial superantigens and quickly acquire an anergic phenotype that impedes their cognate antimicrobial function: defining a novel mechanism of superantigen-induced immunopathology and immunosuppression. PLoS Biol. 2017 Jun;15(6):e2001930.

15 Sakala IG, Kjer-Nielsen L, Eickhoff CS, Wang X, Blazevic A, Liu L, et al. Functional Heterogeneity and Antimycobacterial Effects of Mouse Mucosal-Associated Invariant T Cells Specific for Riboflavin Metabolites. J Immunol. 2015 Jul;195(2):587-601.

16 Ussher JE, Bilton M, Attwod E, Shadwell J, Richardson R, de Lara C, et al. CD161++ CD8+ T cells, including the MAIT cell subset, are specifically activated by IL-12+IL-18 in a TCR-independent manner. Eur J Immunol. 2014 Jan;44(1): 195-203.

17 Chiba A, Tamura N, Yoshikiyo K, Murayama G, Kitagaichi M, Yamaji K, et al. Activation status of mucosal-associated invariant $\mathrm{T}$ cells reflects disease activity and pathology of systemic lupus erythematosus. Arthritis Res Ther. 2017 Mar; 19(1):58

18 Jo YG, Choi HJ, Kim JC, Cho YN, Kang JH, Jin $\mathrm{HM}$, et al. Deficiencies of Circulating $\mathrm{Mu}$ cosal-associated Invariant T Cells and Natu- ral Killer T Cells in Patients with Multiple Trauma. J Korean Med Sci. 2017 May;32(5): $750-6$.

19 Martin E, Treiner E, Duban L, Guerri L, Laude H, Toly C, et al. Stepwise development of MAIT cells in mouse and human. PLoS Biol. 2009 Mar;7(3):e54.

20 Cho YN, Kee SJ, Kim TJ, Jin HM, Kim MJ Jung HJ, et al. Mucosal-associated invariant T cell deficiency in systemic lupus erythematosus. J Immunol. 2014 Oct;193(8):3891-901.

21 Easton R, Balogh ZJ. Peri-operative changes in serum immune markers after trauma: a systematic review. Injury. 2014 Jun;45(6):93441.

22 Parekh VV, Singh AK, Wilson MT, OlivaresVillagómez D, Bezbradica JS, Inazawa $\mathrm{H}$, et al. Quantitative and qualitative differences in the in vivo response of NKT cells to distinct alpha- and beta-anomeric glycolipids. J Immunol. 2004 Sep;173(6):3693-706.

23 Van Kaer L, Parekh VV, Wu L. The response of CD1d-restricted invariant NKT cells to microbial pathogens and their products. Front Immunol. 2015 May;6:226.

24 Kang SJ, Jin HM, Won EJ, Cho YN, Jung HJ, Kwon YS, et al. Activation, Impaired Tumor Necrosis Factor- $\alpha$ Production, and Deficiency of Circulating Mucosal-Associated Invariant T Cells in Patients with Scrub Typhus. PLoS Negl Trop Dis. 2016 Jul;10(7):e0004832.

25 Leeansyah E, Ganesh A, Quigley MF, Sönnerborg A, Andersson J, Hunt PW, et al. Activation, exhaustion, and persistent decline of the antimicrobial MR1-restricted MAIT-cell population in chronic HIV-1 infection. Blood. 2013 Feb;121(7):1124-35.

26 Wang JJ, Macardle C, Weedon H, Beroukas $\mathrm{D}$, Banovic T. Mucosal-associated invariant T cells are reduced and functionally immature in the peripheral blood of primary Sjögren's syndrome patients. Eur J Immunol. 2016 Oct; 46(10):2444-53.

27 Kwon YS, Cho YN, Kim MJ, Jin HM, Jung HJ, Kang JH, et al. Mucosal-associated invariant $\mathrm{T}$ cells are numerically and functionally deficient in patients with mycobacterial infection and reflect disease activity. Tuberculosis (Edinb). 2015 May;95(3):267-74.

28 Wherry EJ. T cell exhaustion. Nat Immunol. 2011 Jun;12(6):492-9.

29 Horton JW. Cellular basis for burn-mediated cardiac dysfunction in adult rabbits. Am J Physiol. 1996 Dec;271(6 Pt 2):H2615-21.
30 Tao L, Liu HR, Gao F, Qu Y, Christopher TA, Lopez BL, et al. Mechanical traumatic injury without circulatory shock causes cardiomyocyte apoptosis: role of reactive nitrogen and reactive oxygen species. Am J Physiol Heart Circ Physiol. 2005 Jun;288(6):H2811-8.

31 Wu H, Wang G, Li S, Zhang M, Li H, Wang K. TNF- $\alpha$ - mediated-p38-dependent signaling pathway contributes to myocyte apoptosis in rats subjected to surgical trauma. Cell Physiol Biochem. 2015;35(4):1454-66.

32 Kumar V, Ahmad A. Role of MAIT cells in the immunopathogenesis of inflammatory diseases: new players in old game. Int Rev Immunol. 2018;37(2):90-110.

33 Wieland E, Shipkova M. Lymphocyte surface molecules as immune activation biomarkers. Clin Biochem. 2016 Mar;49(4-5):347-54.

34 Motamedi M, Xu L, Elahi S. Correlation of transferrin receptor (CD71) with Ki67 expression on stimulated human and mouse $\mathrm{T}$ cells: the kinetics of expression of T cell activation markers. J Immunol Methods. 2016 Oct; 437:43-52.

35 Sachdeva M, Fischl MA, Pahwa R, Sachdeva $\mathrm{N}$, Pahwa S. Immune exhaustion occurs concomitantly with immune activation and decrease in regulatory $\mathrm{T}$ cells in viremic chronically HIV-1-infected patients. J Acquir Immune Defic Syndr. 2010 Aug;54(5): $447-54$.

$36 \mathrm{Xu} \mathrm{W}$, Larbi A. Markers of T Cell Senescence in Humans. Int J Mol Sci. 2017 Aug;18(8):18.

37 Jiang J, Wang X, An H, Yang B, Cao Z, Liu Y, et al. Mucosal-associated invariant T-cell function is modulated by programmed death-1 signaling in patients with active tuberculosis. Am J Respir Crit Care Med. 2014 Aug;190(3):329-39.

38 Hengst J, Strunz B, Deterding K, Ljunggren HG, Leeansyah E, Manns MP, et al. Nonreversible MAIT cell-dysfunction in chronic hepatitis $C$ virus infection despite successful interferon-free therapy. Eur J Immunol. 2016 Sep;46(9):2204-10

39 Hayashi E, Chiba A, Tada K, Haga K, Kitagaichi $M$, Nakajima $S$, et al. Involvement of Mucosal-associated Invariant T cells in Ankylosing Spondylitis. J Rheumatol. 2016 Sep; 43(9):1695-703.

40 Heizmann O, Koeller M, Muhr G, Oertli D, Schinkel C. Th1- and Th2-type cytokines in plasma after major trauma. J Trauma. 2008 Dec;65(6):1374-8. 